This article has been accepted for publication in journal PRECISION AGRICULTURE, published by Springer.

The final authenticated version is available online at. doi.org/10.1007/s11119-019-09640-2

Terms of use see Springer article sharing policy https://www.springerpub.com/journalarticle-sharing-policies for archived author accepted manuscripts (AAMs) of subscription articles. 


\section{Hyperspectral remote sensing of grapevine drought stress}

\section{Zovko, U. Žibrat, M. Knapič, M. Bubalo Kovačić \& D. Romić}

\section{Precision Agriculture}

An International Journal on Advances in Precision Agriculture

ISSN 1385-2256

Precision Agric

DOI 10.1007/s11119-019-09640-2
Volume 14, Number 5, October 2013

\section{ONLINE FIRST}

\section{Precision Agriculture}

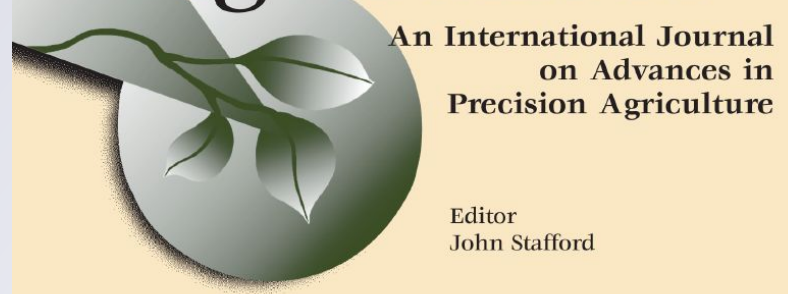

Springer 
Your article is protected by copyright and all rights are held exclusively by Springer Science+Business Media, LLC, part of Springer Nature. This e-offprint is for personal use only and shall not be self-archived in electronic repositories. If you wish to selfarchive your article, please use the accepted manuscript version for posting on your own website. You may further deposit the accepted manuscript version in any repository, provided it is only made publicly available 12 months after official publication or later and provided acknowledgement is given to the original source of publication and a link is inserted to the published article on Springer's website. The link must be accompanied by the following text: "The final publication is available at link.springer.com". 


\title{
Hyperspectral remote sensing of grapevine drought stress
}

\author{
M. Zovko ${ }^{1}$ (D) U. Žibrat ${ }^{2}$ M. Knapič ${ }^{2}$ M. Bubalo Kovačić ${ }^{1} \cdot$ D. Romić ${ }^{1}$
}

(c) Springer Science+Business Media, LLC, part of Springer Nature 2019

\begin{abstract}
In karst landscapes stony soils have little water holding capacity; the rational use of water for irrigation therefore plays an important management role. Because the water holding capacity is not homogenous, precision agriculture approaches would enable better management decisions. This research was carried out in an experimental vineyard grown in an artificially transformed karst terrain in Dalmatia, Croatia. The experimental design included four water treatments in three replicates: (1) fully irrigated, based on $100 \%$ crop evapotranspiration ( $\mathrm{ET}_{\mathrm{c}}$ ) application (N100); (2 and (3) deficit irrigation, based on 75\% and 50\% $\mathrm{ET}_{\mathrm{c}}$ applications (N75 and N50, respectively); and (4) non-irrigated (N0). Hyperspectral images of grapevines were taken in the summer of 2016 using two spectral-radiance (W sr ${ }^{-1} \mathrm{~m}^{-2}$ ) calibrated cameras, covering wavelengths from 409 to $988 \mathrm{~nm}$ and 950 to $2509 \mathrm{~nm}$. The four treatments were grouped into a new set consisting of: (1) drought (N0); and (2) irrigated (the remaining three treatments: N100, N75, and N50). The images were analyzed using Partial Least Squares-Discriminant Analysis (PLS-DA), and treatments were classified using PLS-Single Vector Machines (PLS-SVM). PLS-SVM demonstrated the capability to determine levels of grapevine drought or irrigated treatments with an accuracy of more than $97 \%$. PLS-DA identified relevant wavelengths, which were linked to $\mathrm{O}-\mathrm{H}, \mathrm{C}-\mathrm{H}$, and $\mathrm{N}-\mathrm{H}$ stretches in water, carbohydrates and proteins. The study presents the applicability of hyperspectral imaging for drought stress assessment in grapevines, even though temporal variability needs to be taken into account for early detection.
\end{abstract}

Keywords Vineyard · Irrigation · Water stress $\cdot$ Hyperspectral imagery $\cdot$ Soil $\cdot$ Precision agriculture

\section{Introduction}

Karst landscapes characterized by uplifted carbonate rocks are especially widespread along the Croatian Adriatic coast and islands displaying considerable spatial variability due to contrast in relief, bedrock composition and structure, and other factors (Romic et al. 2012). In such conditions, rural area faces a lack of arable land. Karst landscapes have a great

\author{
M. Zovko \\ mzovko@agr.hr \\ Faculty of Agriculture, University of Zagreb, Zagreb, Croatia \\ 2 Agricultural Institute of Slovenia, Ljubljana, Slovenia
}


potential for providing cultivated land. In many parts of the Mediterranean karst terrains have been directly modified to enhance their agricultural potential. In last two decades, in Croatia, more than 5000 ha of karst stony terraces and steep slopes have been remediate by stone crushing to create larger and flatter areas for cultivation and to make the land suitable for agricultural production, mostly for grapevine and olive production. After the deforestation, new grapevines and olive trees are planted, particularly on the slopes exposed to the sun and sheltered from strong winds. The karst areas along Croatian coast benefits from Mediterranean climate with warm to hot, dry summers, and frequent winds, conditions that favor organic vineyard management.

Karst landscapes, however, are highly fragile and vulnerable to anthropogenic as well as climatic stresses. In stony and gravelly soils, rainwater percolates rapidly downward through the soil layers. Moreover, soil obtained after Karst reclamation is characterized by high share of stones and rock fragments, having variable share of fine soil fraction and low water holding capacity. Thus, the lack of moisture can be an important risk indicator in wine production within these areas. Drought stress is one of the biggest challenges in crop production (Pennisi 2008), and arises from insufficient rainfall and soil water during the growing season (Vadez et al. 2011). Climate change projections show a decrease in the number of rainy days, leading to increased risk of drought (Vadez et al. 2011).

Karst freshwater constitutes by far the main source of drinking water and its use for irrigation is often unsustainable. Even more, the uneven volume and depth of karstic limestone aquifers are often make the drilling wells and water extraction difficult and highly expensive.

The rational use of water for irrigation plays an important role in managing vineyards within karst landscape. Winemakers have recognized the importance of good irrigation management to optimize wine water stress in stony soils with little water holding capacity. However, because irrigated viticulture within these very specific environmental conditions is relatively new, the potential of different approaches/measurement techniques that could help winemakers to define vine water status for guiding irrigation is still evolving.

Vine water status can be assessed through soil water measurements and the use of physiological indicators. However, water measurements in stony karst soils, where rock fragments are dominant over the fine earth fraction, are especially challenging because: (1) the very coarse nature can pose soil contact problems for the majority of the available soil moisture monitoring devices (Al-Yahyai et al. 2006); and (2) soils made by rock-ploughing show great within-field variability (e.g. the proportion of gravel can range from 40 to more than $70 \%$ ) and significantly more probes are required for accurate assessment of soil water content, and a significantly larger number of probes is required for accurate assessment of soil-water content. Under such conditions, irrigation scheduling should be mainly based on vine water status. Current standard procedures include measurements of individual vines (plants), leading to extensive and time-consuming field work, which is subject to measurement and sampling errors (Rodriguez-Perez et al. 2007).

Understanding plant responses to drought stress requires information from the molecular level to that of the whole plant (Chaves et al. 2003). Remote sensing applications allow for a reliable and quick non-destructive assessment of water status in plants (Behman et al. 2014) on different spatial scales (e.g., whole plants or individual leaves). Sensors can detect changes in photosynthetic activity, which are linked to biotic and abiotic stress in plants (Matese and Di Genaro 2014). Hyperspectral imaging combines the benefits of imaging and spectroscopy techniques (Mahesh et al. 2008), since it collects both spatial and spectral data, and combines them in a 3D hypercube. The spectral signature (the amount of reflected light as a function of wavelength) obtained in this way is based on the physical 
and chemical properties of the material examined, and is therefore unique (Ravikanth et al. 2015), and can provide significant improvements in assessing vineyard biophysical and quality parameters (Zarco-Tejada et al. 2005; Diago et al. 2014).

Spectral signatures of plants are influenced by several factors, linked to specific areas of the light spectrum. In the visible part of the spectrum $(400-700 \mathrm{~nm})$, pigments are prevalent (e.g., chlorophyll, carotenoids, anthocyanins). In the near infrared region (NIR, 700-1000 nm), leaf morphology and structure influence signatures, while short-wave infrared (SWIR, 1000-2500 nm) reflectance is influenced by water and metabolites (e.g., cellulose and proteins) (Behman et al. 2014, Matese and Di Genaro 2014). While changes in pigment structure can be visible to the naked eye, variations in the NIR and SWIR regions are invisible (Elsayed et al. 2011). However, changes in the SWIR region occur prior to the development of visible symptoms, and hyperspectral imaging enables presymptomatic detection of stress in plants (Rumpf et al. 2010; Behman et al. 2014). Stress conditions induce changes in plant physiology and leaf structure, which in turn influence the spectral signatures (Wahabzada et al. 2016; Govender et al. 2009). Appropriate spectral analyses can detect these changes and can be used to characterize the plant's physiological state, and assess genotype-specific responses to biotic and abiotic stresses (Mahlein et al. 2012; Wahabzada et al. 2015).

Spectral analyses can be performed by utilizing only selected parts of the light spectrum or by using vegetation indices. These are calculated based on combinations of a few selected wavelengths, associated with specific morphological and physiological parameters, such as chlorophyll content (Fiorani et al. 2012). Vegetation indices have been successfully applied to determine plant responses to stress (Kim et al. 2011; Behman et al. 2014). Spectral indices can also be used as explanatory variables in classification algorithms, such as support vector machines (Rumpf et al. 2010; Behman et al. 2014). But all indices suffer from the same drawback, i.e. they utilize only selected wavelengths, ignoring most of the information that's available in hyperspectral data. Multivariate methods (such as partial least squares regression) and machine learning algorithms (e.g. support vector machines) have been utilized to develop models for reliable detection of abiotic and biotic stress in plants (Vigneau et al. 2011; Mahlein et al. 2012; Römer et al. 2012; Susič et al. 2018).

This research was carried out in a Babic (Croatian autochthonous cultivar) vineyard organically managed and grown on artificially created soils with at least $80 \%$ of gravel $(>25 \mathrm{~mm})$ and high variability of soil-available water. Within this paper, the applicability of hyperspectral imagery to detect water status of grapevine plants under non-irrigated and irrigated conditions using reflectance measurements was tested. The hypothesis was that hyperspectral imaging will enable reliable identification of plant water stress and its severity. Furthermore, the SWIR spectral region was expected to be of higher importance in water stress detection than visible-near infrared wavelength region (VNIR).

\section{Methods}

\section{Overview of environmental and experimental conditions}

The irrigation experiment was conducted over three consecutive years (2014-2016) at a commercial organically managed vineyard (Vitis vinifera L.) of 7-year old "Babic" vines $(0.8 \times 2.0 \mathrm{~m}$ spacing $)$ located in Šibensko kninska county in the wine producing 


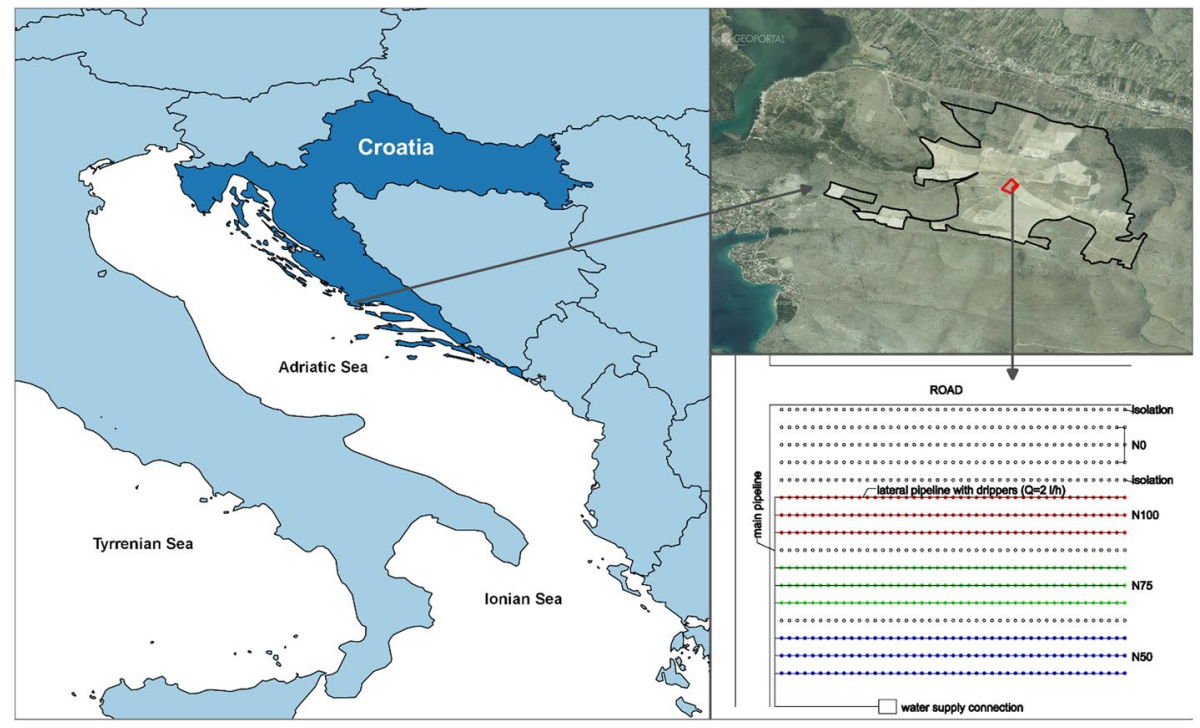

Fig. 1 Geographical setting of the study area, aerial photograph of the study area and maps of the vineyard plot with their respective treatments

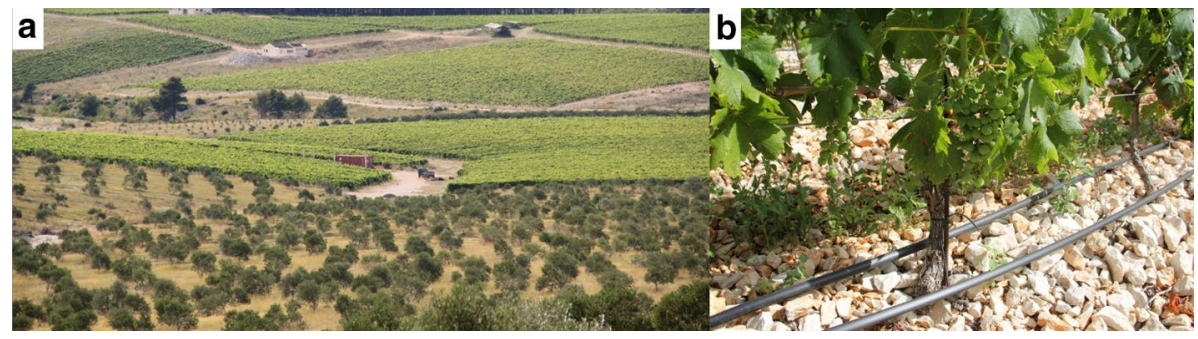

Fig. 2 Photographs of vineyard features in the study area $\mathbf{a}$ and $\mathbf{b}$

region of Croatia with Mediterranean climate (Fig. 1). The substrate was produced by stone crushing to the depth of approximately $0.6 \mathrm{~m}$. The native soil types in the area were regosol and shallow brown soil on limestone, which became transformed into cultivated karst and such a land was mainly dedicated to the planting of wine grape and olives (Fig. 2a, b). The distribution of rock fragments in such substrate is highly variable regarding the fragments share, shape and size within the root zone. In the surface layer to the depth of $25 \mathrm{~cm}$ the share of rock fragments $>25 \mathrm{~mm}$ in diameter amounts $81 \%$. The texture of fine soil particles with diameter below $2 \mathrm{~mm}$ is silty clay loam mixed with the small rock fragments left after crushing with the size of fine and coarse sand. Underlying layer in the depth of $25-60 \mathrm{~cm}$ is dominated by large blocks of crushed rock and coarse stone fragments with the share of fine particles of 6 to $15 \%$. Consequently, water retention capacity is low (3.1-6.7 vol\%), and very low available soil moisture (3.9-6.1 vol\%). Fine soil fraction is alkaline $(\mathrm{pHKCl}=7.6)$, containing variable content of $\mathrm{CaCO}_{3}(10-48 \%)$, as well and humus content (3.5-6\%). 
Average annual precipitation of the area ranges from $557 \mathrm{~mm}$ to $1200 \mathrm{~mm}$ being quite evenly distributed over the year, and the driest from May to September. Babic cv. (Vitis vinifera $\mathrm{L}$.) vines were grafted on Richter 110 rootstock and trained to a vertically shootpositioned trellis system. Weather variables including air temperature, relative air humidity, precipitation, leaf moisture, wind speed and direction, solar radiation and soil moisture, were recorded in 10 mins intervals at an automated weather station located at the study site (Pinova Meteo Weather Station http://pinova-meteo.com/hr_HR). The reference evapotranspiration $\left(\mathrm{ET}_{0}\right)$ was used, along with a crop coefficient $\left(\mathrm{K}_{\mathrm{c}}\right)$ to compute the amount of water required daily by the vines, crop evapotranspiration $\left(\mathrm{ET}_{\mathrm{c}}\right)$ using the equation $\mathrm{ET}_{\mathrm{c}}=\mathrm{K}_{\mathrm{c}} \times \mathrm{ET}_{0}$ (Allen et al. 1998). The values of $\mathrm{K}_{\mathrm{c}}$ were derived from previous experiments (Girona et al. 2006; Marsal et al. 2008) and were estimated for the specific stage of the canopy development as follows: for the initial stage $\mathrm{K}_{\mathrm{c}} \mathrm{in}=0.2$, for the mid-season until harvest $\mathrm{K}_{\mathrm{c}}$ mid $=0.66$, and for the late stage $\mathrm{K}_{\mathrm{c}}$ end $=0.25$. In the study area, growing period starts in Mid-March by bud burst, and ends in late October by leaf fall. Drip irrigation was applied based on the daily water balance and the treatments consisted of:

- Rain fed treatment (non-irrigated) as a control (N0),

- Irrigation treatment corresponding to $50 \% \mathrm{ET}_{\mathrm{c}}(\mathrm{N} 50)$

- Irrigation treatment corresponding to $75 \% \mathrm{ET}_{\mathrm{c}}(\mathrm{N} 75)$

- Irrigation treatment corresponding to $100 \% \mathrm{ET}_{\mathrm{c}}(\mathrm{N} 100)$

Irrigation experiment was conducted on three separate rows of grapevines with 50 vines each, with one row of isolation. The drip lines were placed along each row with $2 \mathrm{~L} \mathrm{~h}^{-1}$ emitters placed $0.6 \mathrm{~m}$ distance. Irrigation water addition per treatment was adjusted by installing 1, 2 or 3 pipe lines, applying the same irrigation time for each treatment. Web based GALCON GSI irrigation controller (http://galconc.com/) was used for the remote irrigation system management. Irrigation began when the sum of decade values of $\mathrm{ET}_{\mathrm{c}}$ exceeded the sum of precipitation, that was in the first decade of June in 2015, and second decade of June in 2016. In 2016, irrigation was applied in 41 occasions and was ended in the third decade of August grapevines were managed organically, and all management practices were the same in all plots.

For spectral analyses, five plants from each line were randomly selected. Thus, each treatment consisted of 15 plants for a total of 60 plants. Hyperspectral images of the selected grapevines were captured in 1 day, on 26 July 2016, using two cameras, Hyspex VNIR-1600 (spectral range from 400 to $990 \mathrm{~nm}$, bandwidth $3.6 \mathrm{~nm}$ ) and SWIR-384 (950 to $2500 \mathrm{~nm}$, bandwidth $5.4 \mathrm{~nm}$ ) (Norsk Elektro Optikk, Norway), yielding a total of 448 spectral bands. The cameras were mounted on a tripod with a rotation stage, and moved around the vineyard with a tractor. Image acquisition started at 9:00 and was completed within a time span of $2 \mathrm{~h}$, in order to minimize light-source temperature drift and stabilize spatial lighting uniformity (Piqueras et al. 2012). A gray diffuse reflectance standard Zenith Lite ${ }^{\mathrm{TM}}$ of $20 \%$ reflectance was used as a reference for incoming sunlight. Because this reference panel has a known reflectance, it enabled the calculation of reflectance of sunlight off plants (Eq. 1). The hyperspectral images were calibrated to radiance units $\left(\mathrm{W} \mathrm{sr}-1 \mathrm{~m}^{-2}\right.$ ). The radiometric calibration process accounts for sensor characteristics and is an obligatory part of every spectral pre-processing. Spectral radiance described the amount of energy reflected off a surface, disregarding the amount of incoming energy or light. Leaf-area (i.e. pixels containing spectral information from leaves) and reference plate pixels (i.e. pixels containing spectral information from the reference plate) were extracted by classifying each image using spectral information 
divergence (Du et al. 2004). The latter is a classification method which compares image pixel data with a referential spectral library. In this study the spectral library for spectral information divergence consisted of four classes: (1) reference plate, (2) leaf-area, (3) ground, and (4) other (e.g. metallic wires holding the vines). The smaller the divergence (i.e. greater dissimilarity) between the image pixels and spectral library references, the higher the probability that they belong to the same material. Using this classification image content was separated into four classes, of which only reference plate and leafarea pixels were retained for further analysis. These extracted radiance values were further normalized and converted to net reflectance using the following equation:

$$
R_{i}=\frac{R_{r o i}-R_{d}}{R_{s t d}-R_{d}} * 0.2
$$

where $R_{i}$ is normalized reflectance for $i$-th plant (\%), $R_{\text {roi }}$ is radiance value of $i$-th plant (W st ${ }^{-1} \mathrm{~m}^{-2}$ ), $\mathrm{R}_{\text {std }}$ is radiance value of gray reference, and $\mathrm{R}_{\mathrm{d}}$ is dark current of the sensor. By calibrating the images to radiance and calculating the reflectance, a direct comparison between data acquired by different spectral sensors is possible.

Pixel spectral signatures were normalized using area normalization (the spectral signature of each pixel was divided by the area under the curve) to reduce the effects of plant geometry (i.e. plants are not smooth and reflect light at different angles), and the mean spectra for each plant were calculated. Plant reflectance data were smoothed using a Savitzky-Golay filter with a 2 nd order polynomial. The data smoothing process removes small, localized, peaks in the spectral signatures, thus further removing random noise effects. The 2 nd order derivatives with a symmetric window width of 7 points (a smoothing array of filter size, describing the number of bands to the left and right of a particular spectral band) were then calculated, to emphasize small spectral variations and remove scattering effects. Because the smoothing array was symmetrical it could not have been applied at both ends of the spectrum, hence the derivative spectra are shorter than the original data.

Patterns in the hyperspectral data, due to differing levels of drought stress, were explored using Partial least squares-Discriminant analysis (PLS-DA) (Ballabio and Consonni 2013). This is a multivariate statistical method, similar to principal component analysis. It finds a linear regression model by projecting predicted and observable variables onto a new space, called components or factors. The number of these new components is the same as the number of variables, but in practice only up to ten carry useful information, and the remaining containing mostly noise. In PLS-DA is a variant of classic PLS, where the dependent variably is categorical. PLS is particularly suited when there are more variables than observations (the data matrix is wide) and there is multicollinearity between the independent variables (such as between spectral bands). A standard deviation weighting process, using the standard deviation of each treatment group, was used on all variables, and the PLS-DA models were validated with the full, leave-one-out cross-validation (one plant was used as a test set while the rest were used as a training set, and this process was repeated 60 times, i.e. the number of plants in this study). Selection of relevant spectral regions was performed using the variable in projection scores (VIP) (Chong and Jun 2005). This algorithm estimates the importance of each spectral band in a PLS model and can be used for variable selection. The cut-off is set at 1, i.e. variables with VIP scores of 1 or more are considered important to the given model. For identification of outliers the Hotelling $\mathrm{T}^{2}$ test was applied, which is a generalization of Student's t-statistic, used for multivariate distributions. 
The PLS-DA factor scores were then used as explanatory variables in the support vector machine classification scheme (PLS-SVM) (Belousov et al. 2002). Support vector machines (SVM) are supervised classification algorithms, which enable non-linear classifications. The gamma values and capacity factors (c) for each classification were determined by performing a grid search on a log scale. Gamma and c are parameters of a non-linear SVM, influencing the classification reliability. A high gamma leads to high bias and low variance, and a high capacity factor (c) leads to good separability, but can lead to overfitting (i.e. the model cannot generalize). Similar to PLS-DA, standard deviation weighting was applied to all components. The PLS-SVM models were validated using 10-fold cross-validation. The optimal number of PLS-DA components was determined by using root mean square error cross-validation (RMSECV). PLS-DA showed the presence of outliers belonging to Line 1 of the N0 treatment. Since all five plants were outliers, forming their own cluster, they were excluded from further analysis (Fig. 3).

Spectral signatures of each plant were separated and extracted using ENVI 5.1 (Exelis Visual Information Solutions, Inc., USA). The extracted data were pre-processesed, and PLS-SVM evaluation and VIP analyses performed in R (R Core Team 2015), while PLS-DA and PLS-SVM classifications were performed in Unscrambler 10.3 (CAMO Software, Norway).
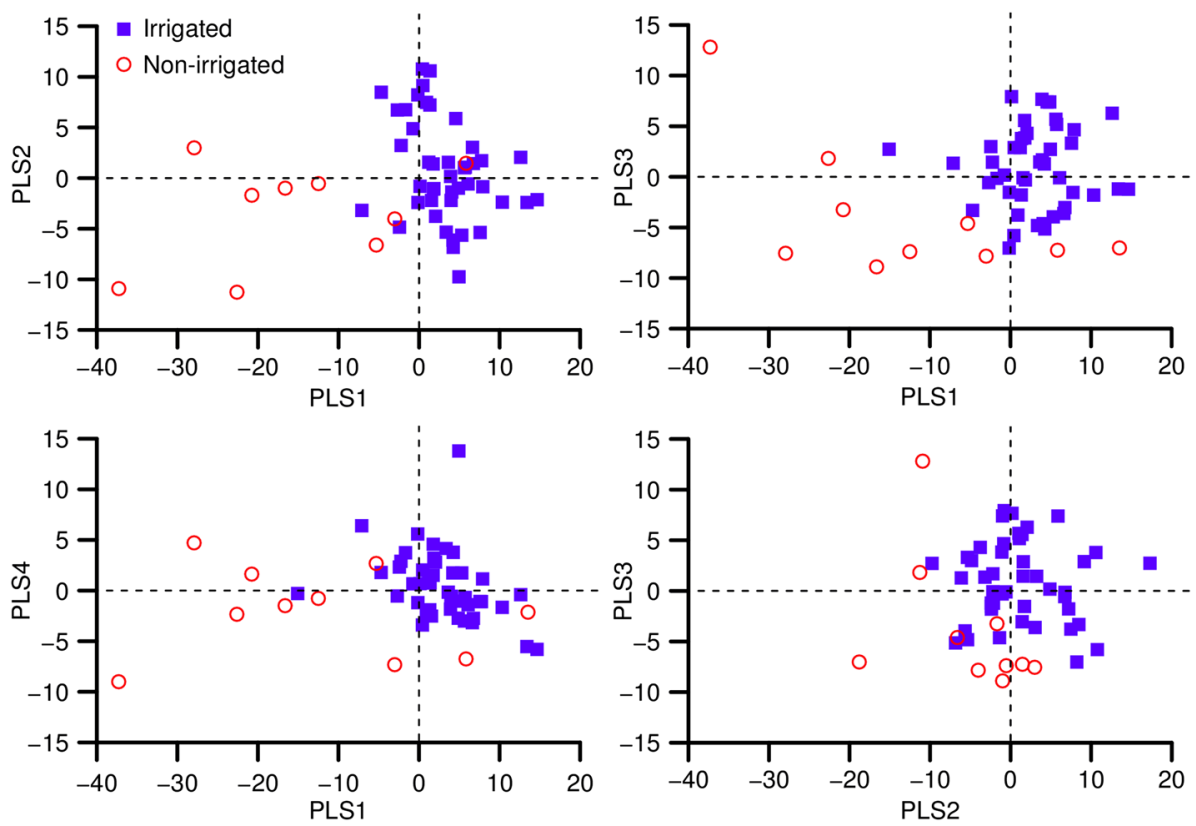

Fig. 3 PLS-DA score plots of water availability variability using mean spectra of each plant. Shown are combinations of selected PLS-DA components 


\section{Results and discussion}

The PLS-SVM successfully determined drought stress in grapevines with a classification success of $98.2 \%$. One plant was misclassified in the drought stress, yielding a specificity of 0.9 and sensitivity of 1 (for more explanation see Table 1). The PLS-DA showed a good separation of both groups, with an RMSECV of 0.16 , with the selected components explaining $83 \%$ of the variance (Table 1, Fig. 3). Plants in the irrigated group showed a lower variability than plants in drought. Identification of water availability groups (i.e., treatments) reached a similar success, with $97.8 \%$ instances correctly classified. Both PLSSVM and PLS-DA showed a good separation between the N50 and N75 + N100 treatments, but one plant from N75 was misclassified into N100. The sensitivity was lowest for N75, at 0.933, while specificity was lowest for N100, at 0.97 (Table 1, Fig. 4). The selected PLS-DA components explained $81 \%$ of the variance, with a RMSECV of 0.21 (Table 1). By reducing the number of classes in a classification scheme, model reliability can be increased. In this study the differences between severe drought (N0) and irrigated treatments $(\mathrm{N} 50+\mathrm{N} 75+\mathrm{N} 100)$ was first tested thus making it a two-class problem (Zovko et al. 2017). The differences between the irrigated treatments (N50, N75, and N100), which were also tested (Fig. 3) where two classes (N75 and N100) were more similar to each other, than to the third class (this can be seen by comparing their sensitivities and specificities). Soil obtained after Karst reclamation is characterized by high share of stones and rock fragments, having variable share of fine soil fraction and low water holding capacity. In stony soils, physical (texture) parameters and hydraulic characteristics that affect plant water status may be very variable even between closely spaced points. Therefore, considerable variability can occur in infiltration and evaporation rates, capillary movement and the amount of plant-available water in soil as well as in their impact on vine physiology. At the site under consideration (FIRE site in High Tatras), at a depth of $50 \mathrm{~cm}$ below the soil surface, up to $49 \%$ of the soil volume consists of rock fragments larger than $1 \mathrm{~cm}$ in diameter (Novák et al. 2008). Such high relative content of stones significantly influences both soil water retention and hydraulic conductivity and their determination thus needs a special attention.

Drought and treatment identification analyses showed a similar pattern of relevant wavelengths (Fig. 4). In the visible part of the spectrum, only the reflectance at $583 \mathrm{~nm}$ was relevant, where irrigated plants exhibited lower reflectance than plants in drought stress

Table 1 Summary of PLS-DA and PLS-SVM analyses

\begin{tabular}{|c|c|c|c|c|c|c|c|c|c|}
\hline \multirow[t]{2}{*}{ Analyses } & \multicolumn{2}{|l|}{ PLS-DA } & \multicolumn{2}{|c|}{ SVM } & \multicolumn{4}{|c|}{ Accuracy (\%) } & \multirow[t]{2}{*}{ Treatment group } \\
\hline & $\operatorname{Var}[\%]$ & RMSECV & $\mathrm{c}$ & gamma & Ts & $\mathrm{CV}$ & Sensitivity & Specificity & \\
\hline Drought & 83 & 0.16 & 5.18 & 0.01 & 100 & 98.2 & 0.9 & 1 & \\
\hline Treatment & 81 & 0.21 & 1.39 & 0.01 & 100 & 97.3 & $\begin{array}{l}1 \\
0.93 \\
1\end{array}$ & $\begin{array}{l}0.97 \\
1 \\
1\end{array}$ & $\begin{array}{l}\text { N100 } \\
\text { N75 } \\
\text { N50 }\end{array}$ \\
\hline
\end{tabular}

Sensitivity (true positive rate) measures the percentage of correctly identified cases belonging to a certain class, while specificity (true negative rate) measures the percentage of cases that were correctly identified as not belonging to a certain class

Var explained variance of the selected PLS components; RMSECV root mean squared error of cross-validation of selected PLS components; $T s$ train set; $C V$ cross-validation 

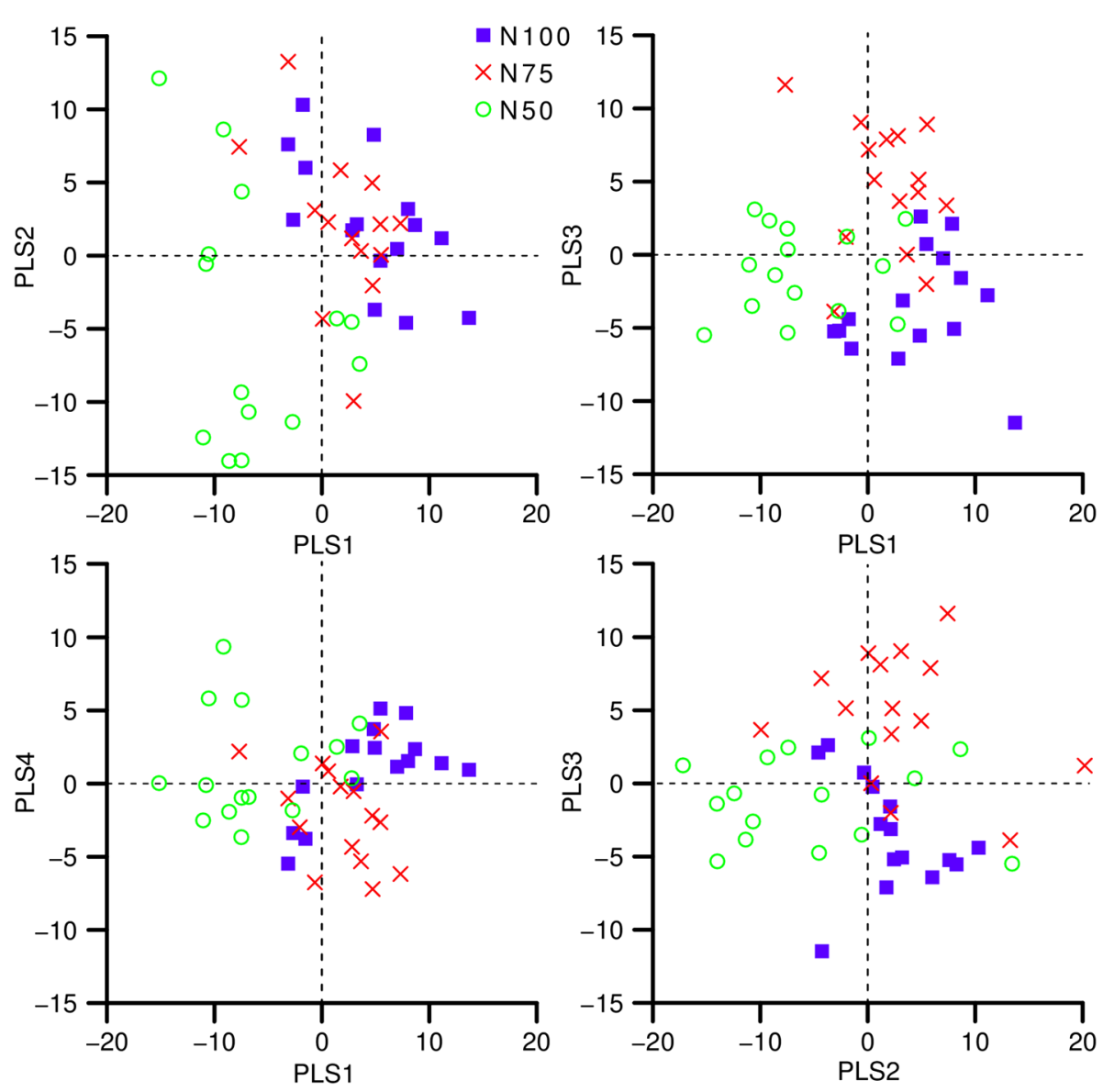

Fig. 4 PLS-DA score plots of treatment variability using mean spectra of each plant. Shown are combinations of selected PLS-DA components. N100, N75, and N50 are the irrigated treatment groups

(Fig. 5). Changes in reflectance around $550 \mathrm{~nm}$ are linked to adjustments of photoprotective pigments in leaves, such as anthocyanins (Steele et al. 2009). Photoprotective pigments alleviate oxidative damage by drought stress to plant tissue. These protective pigments are very susceptible to oxidative damage, and their concentrations decrease with increasing stress. Changes to pigment structure also include differences in the Chl- $a$ to Chl- $b$ ratio. The results of this research showcase this at $738 \mathrm{~nm}$, where irrigated vines showed lower reflectance than water deficient vines. This is mainly due to differences in Chl- $a$, which reflects light around 440 and $680 \mathrm{~nm}$. Pigments in plants, however, are always bound to proteins, which shifts their reflectance spectrum (Moss and Loomis 1952).

Reflectance in the NIR and SWIR spectral regions is linked to chemical and physical characteristics of leaves, such as carbohydrates, proteins, and leaf water content (Qiao et al. 2007; Kim et al. 2015), as well as lignin and cellulose content (Li et al. 2015). The water absorption bands in the $1300-2500 \mathrm{~nm}$ region show a high sensitivity to leaf water content. These findings correspond to literature data, where water-related bands at 975, 1200, 1470, 1930, and $2500 \mathrm{~nm}$ were identified (Cao et al. 2013; Clevers et al. 2010). Three 


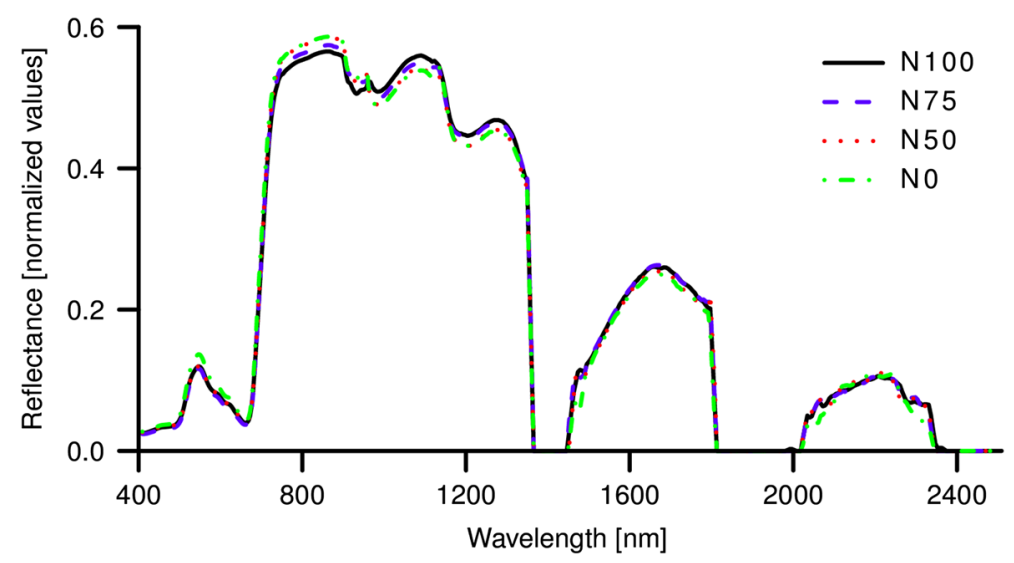

Fig. 5 Normalized reflectance spectra of all treatment groups in the study

wavelengths were identified at the beginning of this region $(1259,1264$, and 1334), all of which are linked to the $\mathrm{O}-\mathrm{H}$ stretch in water (Yin et al. 2017) as well as four more wavelengths, linked to leaf water content (at 1500, 1888, 1954, and $2053 \mathrm{~nm}$ ) (Fig. 6). Identification of watered plants was most reliable, with an F-measure value of 0.97 , while for drought plants it was 0.82 (Zovko et al. 2017). In all of these cases, the N100 treatment exhibited the highest reflectance and N0 the lowest. The spectral signatures of N100 and N75 overlap between 1200 and $1800 \mathrm{~nm}$, leading to reduced classification reliability. These results correspond with the water availability gradient from N100 to N0. The similarity between N100 and N75 is due to the grapevine drought resistance, i.e. their ability to maintain high water potential in the tissues (Vadez et al. 2011).

Metabolic changes of leaf biochemistry are reflected around $1110 \mathrm{~nm}(\mathrm{~N}-\mathrm{H}$ stretch of proteins), and 1200 and $1330 \mathrm{~nm}$ (C-H stretch of carbohydrates and proteins). The irrigated plants showed higher reflectance at these wavelengths, indicating the decomposition of cellulose and proteins in leaves, due to drought stress and oxidative damage to photoprotective pigments in non-irrigated plants. Furthermore, drought induces metabolic changes in plants through increased accumulation of essential amino acids and free sugars

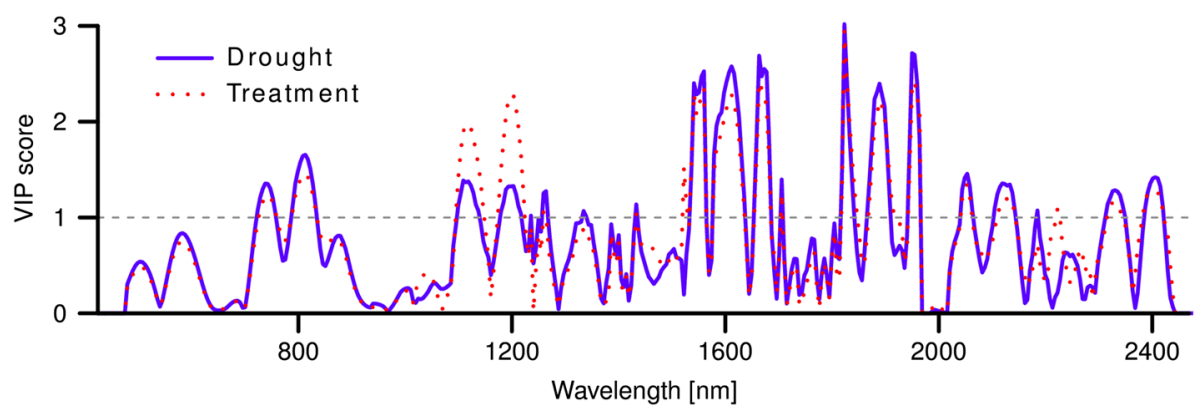

Fig. 6 VIP scores from PLS-DA models of drought stress identification (solid line), and determination of its severity (dashed line). All wavelengths with VIP scores above 1 are considered to be important for the identification of drought stress and its severity 
(Ximénez-Embún et al. 2016). These changes are triggered by several survival adaptations, such as stomatal closure to prevent water loss due to transpiration, and decreased stomatal conductance (Chaves et al. 2009). Drought resistance is therefore a combination of physiological and biochemical adaptations (Ashraf 2009), which in turn are reflected in the plants' spectral signature.

Drought stress and leaf senescence cause a reallocation of resources in the entire plant. Leaf senescence appears in all plants, regardless of water availability. Furthermore, drought-stressed plants suffer from early and accelerated leaf senescence (Munné-Bosch and Alegre 2004). Distinguishing between drought stress and leaf senescence requires detailed spectral information with high spectral and temporal resolution. Within this study, only plants in veraison were included, thus ignoring temporal variations in reflectance. Nevertheless, the success rate of PLS-SVM classifications in identifying drought stress and its severity indicates that the same method could be applied to temporal data and will probably yield similar success (Susič et al. 2018). Therefore, this study indicates that the early identification of drought stress and its severity in vineyards is possible. Stony soil heterogeneity is a challenging for both groups of sensors, because of large stony segments on centimeter or decimeter scales (Coppola et al. 2013). Finally, the effect of stoniness was considered as a possible explanation of the differences frequently observed between the measured hydraulic behavior and that estimated by using pedotransfer functions coarse rock fragments (Mehuys et al. 1975).

\section{Conclusions}

This study demonstrates the application of hyperspectral imaging, combined with partial least squares support vector machine classifications, to determine drought stress and its severity in grapevines. For PLS-SVM classification the SWIR region (with 16 wavelengths identified as important) was identified as being of more importance than VNIR (with 2 wavelengths determined as being important). Spectral signatures of different water availability treatments showed significant differences, allowing for high classification accuracy. Within this initial research, hyperspectral images were collected only once on randomly selected vines, during the vine veraison, which is not sufficient for suitability evaluation of hyperspectral use in vine water status assessment during the growing season, as temporal variability was not included in the analysis. Nevertheless, hyperspectral imaging represents a cost efficient and fast determination of drought stress in grapevines grown on stony karst soils. Furthermore, the identification of wavelengths relevant for the determination of drought stress and its severity can facilitate the development of dedicated sensors, which would increase the cost effectiveness of remote sensing applications for drought detection. Moreover, the successful identification of drought stress severity also enables precision agriculture approaches to drought management, thus reducing resource use. Due to the extremely heterogeneous nature of artificially created karst soil, it is probably needed to include, besides hyperspectral, some other sensors to monitor the vine water status for the purpose of precise vineyard irrigation. This should be the next step in future research endeavors.

Acknowledgments This research has been partially supported in part by Croatian Science Foundation under the Project IP-2016-06-8379, SENSIRRIKA - Advanced sensor systems for precision irrigation in karst landscape, and partially by the Croatian Waters, and by the Slovenian Research Agency (ARRS), Grant P4-0072. 


\section{References}

Allen, R. G., Pereira, L. S., Raes, D., \& Smith, M. (1998). Crop evapotranspiration-guidelines for computing crop water requirements-FAO Irrigation and drainage paper 56. Rome: Food and Agriculture Organization.

Al-Yahyai, R., Schaffer, B., Davies, F. S., \& Muñoz-Carpena, R. (2006). Characterization of soil-water retention of a very gravelly loam soil varied with determination method. Soil Science, 17, 85-93.

Ashraf, M. (2009). Inducing drought tolerance in plants. Biotechnology Advances, 28(1), 169.

Ballabio, D., \& Consonni, V. (2013). Classification tools in chemistry. Part I: Linear models. PLS-DA. Analytical Methods, 5, 3790-3798.

Behman, J., Steinrücken, J., \& Plümer, L. (2014). Detection of early plant stress responses in hyperspectral images. ISPRS Journal of Photogrammetry and Remote Sensing, 93, 98-111.

Belousov, A. I., Verzakov, S. A., \& von Frese, J. (2002). Applicational aspects of support vector machines. Journal of Chemometrics, 16, 482-489.

Cao, Q., Zhegalova, N. G., Wang, S. T., Akers, W. J., \& Berezin, M. Y. (2013). Multispectral imaging in the extended near-infrared window based on endogenous chromophores. Journal of Biomedical Optics, $18(10), 101318$.

Chaves, M. M., Flexas, J., \& Pinheiro, C. (2009). Photosynthesis under drought and salt stress: Regulation mechanisms from whole plant to cell. Annals of Botany, 103(4), 551-560.

Chaves, M. M., Maroco, J. P., \& Pereira, J. S. (2003). Understanding plant responses to drought-From genes to the whole plant. Functional Plant Biology, 30(3), 239-264.

Chong, I. G., \& Jun, C. H. (2005). Performance of some variable selection methods when multicollinearity is present. Chemometrics and Intelligent Laboratory Systems, 78, 103-112.

Clevers, J. G. P. W., Kooistra, L., \& Schaepman, M. E. (2010). Estimating canopy water content using hyperspectral remote sensing data. International Journal of Applied Earth Observation and Geoinformation, 12, 119-125

Coppola, A., Dragonetti, G., Comegna, A., Lamaddalena, N., Caushi, B., Haikal, M. A., et al. (2013). Measuring and modeling water content in stony soils. Soil \& Tillage Research, 128, 9-22.

Diago, M. P., Pou, A., Millan, B., Tardaguila, J., Fernandes, A. M., \& Melo-Pinto, P. (2014). Assessment of grapevine water status from hyperspectral imaging of leaves. Acta Horticulturae (ISHS), 1038, 89-96.

Du, Y., Chang, C. I., Ren, H., Chang, C. C., \& Jensen, J. O. (2004). New hyperspectral discrimination measure for spectral characterization. Optical Engineering, 43(8), 1777-1786.

Elsayed, S., Mistele, B., \& Schmidhalter, U. (2011). Can changes in leaf water potential be assessed spectrally? Functional Plant Biology, 38, 523-533.

Fiorani, F., Rascher, U., Jahnke, S., \& Schurr, U. (2012). Imaging plants dynamics in heterogenic environments. Current Opinion in Biotechnology, 23(2), 227-235.

Girona, J., Mata, M., del Campo, J., Arbonés, A., Bartra, E., \& Marsal, J. (2006). The use of midday leaf water potential for scheduling deficit irrigation in vineyards. Irrigation Science, 24(2), 115-127. https ://doi.org/10.1007/s00271-005-0015-7.

Govender, M., Dye, P. J., Weiersbye, I. M., Witkowski, E. T. F., \& Ahmed, F. (2009). Review of commonly used remote sensing and ground-based technologies to measure plant water stress. Water SA, $35,741-752$.

Kim, Y., Glenn, D. M., Park, J., Ngugi, H. K., \& Lehman, B. L. (2011). Hyperspectral image analysis for water stress detection of apple trees. Computers and Electronics in Agriculture, 77(2), 155-160.

Kim, D. M., Zhang, H., Zhou, H., Du, T., Wu, Q., Mockler, T. D., et al. (2015). Highly sensitive imagederived indices of water-stressed plants using hyperspectral imaging in SWIR and histogram analysis. Scientific Reports, 5, 15919.

Li, X., Sun, C., Zhou, B., \& He, Y. (2015). Determination of hemicellulose, cellulose and lignin in Moso bamboo by near infrared spectroscopy. Scientific Reports, 5, 17210. https://doi.org/10.1038/srep17210.

Mahesh, S., Manickavasagan, A., Jayas, D. S., Paliwal, J., \& White, N. D. G. (2008). Feasibility of nearinfrared hyperspectral imaging to differentiate Canadian wheat classes. Biosystems Engineering, 101(1), 50-57.

Mahlein, A.-K., Steiner, U., Hillnhütter, C., Dehne, H.-W., \& Oerke, E.-C. (2012). Hyperspectral imaging for small-scale analysis of symptoms caused by different sugar beet diseases. Plant Methods, 8,3 .

Marsal, J., Mata, M., Arbones, A., Del Campo, J., Girona J., \& Lopez , G. (2008). Factors involved in alleviating water stress by partial crop removal in pear trees. Tree Physiology, 28, 1375-1382.

Matese, A., \& Di Genaro, S. F. (2014). Technology in precision viticulture: a state of the art review. International Journal of Wine Research, 7, 69-81.

Mehuys, G. R., Stolzy, L. H., \& Letey, J. (1975). Temperature distributions under stones submitted to a diurnal heat wave. Soil Science, 120, 437-441. 
Moss, R. A., \& Loomis, W. E. (1952). Absorption spectra of leaves. Plant Physiology, 27(2), 370-391.

Munné-Bosch, S., \& Alegre, L. (2004). Die and let live: leaf senescence contributes to plant survival under drought stress. Functional Plant Biology, 31(3), 203-216.

Pennisi, E. (2008). The blue revolution, drop by drop, gene by gene. Science, 320(5873), 171-173.

Piqueras, S., Burger, J., Tauler, R., \& de Juan, A. (2012). Relevant aspects of quantification and sample heterogeneity in hyperspectral image resolution. Chemometrics and Intelligent Laboratory Systems, 117, $169-182$.

Qiao, J., Ngadi, M. O., Wang, N., GariePy, C., \& Prasher, S. O. (2007). Pork quality and marbling level assessment using a hyperspectral imaging system. Journal of Food Engineering, 83, 10-16.

R Core Team. R: A language and environment for statistical computing. R Foundation for Statistical Computing, Vienna, Austria. 2015. https://www.R-project.org/.

Ravikanth, L., Singh, C. B., Jayas, D. S., \& White, N. D. G. (2015). Classification of contaminants from wheat using near-infrared hyperspectral imaging. Biosystems Engineering, 135, 73-86.

Rodriguez-Perez, J. R., Riano, D., Carlisle, E., Ustin, S., \& Smart, D. R. (2007). Evaluation of hyperspectral reflectance indexes to detect grapevine water status in vineyards. American Journal of Enology and Viticulture, 58(3), 302-317.

Römer, C., Wahabzada, M., Ballvora, A., Pinto, F., Rossini, M., Panigada, C., et al. (2012). Early drought stress detection in cereals: simplex volume maximisation for hyperspectral image analysis. Functional Plant Biology, 39(11), 878-890.

Romic, M., Zovko, M., Romic, D., \& Bakic, H. (2012). Improvement of vineyard management of Vitis vinifera $\mathrm{L} \mathrm{cv}$ Grk in the Lumbarda Vineyard region (Croatia). Communications in Soil Science and Plant Analysis, 43, 209-218. https://doi.org/10.1080/00103624.2011.638557.

Rumpf, T., Mahlein, K., Steiner, A., Oerke, U., Dehne, H., \& Pluemer, L. (2010). Early detection and classification of plant diseases with support vector machines based on hyperspectral reflectance. Computers and electronics in agriculture, 74(1), 91-99.

Steele, M. R., Gitelson, A. A., Rundquist, D. C., \& Merzlyak, M. N. (2009). Nondestructive estimation of anthocyanin content in grapevine leaves. American Journal of Enology and Viticulture, 60, 87-92.

Susič, N., Žibrat, U., Širca, S., Strajnar, P., Razinger, J., Knapič, M., et al. (2018). Discrimination between abiotic and biotic drought stress in tomatoes using hyperspectral imaging. Sensors and actuators $B$ : Chemical, 273, 842-852. https://doi.org/10.1016/j.snb.2018.06.121.

Vadez, V., Kholova, J., Choudhary, S., Zindy, P., Terrier, M., Krishnamurth, L., et al. (2011). Responses to increased moisture stress and extremes: Whole plant response to drought under climate change. In S. S. Yadav, R. Redden, J. L. Hatfield, H. Lotze-Campen, \& A. E. Hall (Eds.), Crop adaptation to climate change (pp. 186-197). Orford: Chichester-Wiley-Blackwell.

Vigneau, N., Ecarnot, M., Rabatel, G., \& Roumet, P. (2011). Potential of field hyperspectral imaging as a non destructive method to assess leaf nitrogen content in wheat. Field Crops Research, 122(1), 25-31.

Wahabzada, M., Mahlein, A.-K., Bauckhage, C., Steiner, U., Oerke, E.-C., \& Kersting, K. (2015). Metro maps of plant disease dynamics automated mining of differences using hyperspectral images. PLoS ONE, 10(1), e0116902.

Wahabzada, M., Mahlein, A.-K., Bauckhage, C., Steiner, U., Oerke, E.-C., \& Kersting, K. (2016). Plant phenotyping using probabilistic topic models: uncovering the hyperspectral language of plants. Scientific Reports, 6, 22482.

Ximénez-Embún, M. G., Ortego, F., \& Castañera, P. (2016). Drought-stressed tomato plants trigger bottomup effects on the invasive Tetranychus evansi. PLoS ONE, 11, e0145275.

Yin, W., Zhang, C., Zhu, H., Zhao, Y., \& He, Y. (2017). Application of near-infrared hyperspectral imaging to discriminate different geographical origins of Chinese wolfberries. PLOS ONE, 12, e0180534.

Zarco-Tejada, P. J., Berjon, A., Lopez-Lozano, R., Miller, J. R., Martın, P., Cachorro, V., et al. (2005). Assessing vineyard condition with hyperspectral indices: Leaf and canopy reflectance simulation in a row-structured discontinuous canopy. Remote Sensing of Environment, 99, 271-287.

Zovko, M., Žibrat, U., Knapič, M., Bubalo, M., Romić, M., \& Romić, D. (2017). Hyperspectral imagery as a supporting tool in precision irrigation of karst landscapes. Advances in Animal Biosciences, 8(2), 578-582. https://doi.org/10.1017/S2040470017000991.

Publisher's Note Springer Nature remains neutral with regard to jurisdictional claims in published maps and institutional affiliations. 